\title{
The Clinical Development Program of Lixisenatide: A Once-Daily Glucagon-Like Peptide-1 Receptor Agonist
}

\author{
Stephen C. Bain
}

To view enhanced content go to www.diabetestherapy-open.com

Received: May 26, 2014 / Published online: July 16, 2014

(c) The Author(s) 2014. This article is published with open access at Springerlink.com

\section{ABSTRACT}

Lixisenatide (AVE0010) is a once-daily glucagonlike peptide-1 (GLP-1) receptor agonist used in the treatment of type 2 diabetes. Phase II dosefinding and pharmacodynamic studies identified the $20 \mu \mathrm{g}$ once-daily dose as having the optimum combination of efficacy, convenience and tolerability. Lixisenatide was prospectively investigated in a series of 11 multinational, randomised, controlled phase III trials (GLP-1 agonist AVE0010 in paTients with type 2 diabetes mellitus for Glycemic cOntrol and sAfety evaLuation [GetGoal] programme) that included a direct head-to-head study with exenatide. The GetGoal programme established the efficacy and safety profile of lixisenatide $20 \mu \mathrm{g}$ once daily across the spectrum of patients with type 2 diabetes, including patients not treated with anti-diabetic agents, those failing on oral agents and as an adjunct to basal insulin

Electronic supplementary material The online version of this article (doi:10.1007/s13300-014-0073-z) contains supplementary material, which is available to authorized users.

\section{S. C. Bain ( $\square)$}

Institute of Life Science, College of Medicine, Swansea University, Swansea SA2 8PP, UK e-mail: s.c.bain@swansea.ac.uk therapy. The main efficacy endpoints were met in all studies, with the baseline to endpoint reductions in $\mathrm{HbA}_{1 \mathrm{c}}$ consistently ranging from $0.7 \%$ to $1.0 \%$. In a head-to-head comparison with exenatide $10 \mu \mathrm{g}$ twice daily, lixisenatide $20 \mu \mathrm{g}$ once daily was non-inferior for $\mathrm{HbA}_{1 \mathrm{c}}$ reduction, achieved with threefold fewer patients with symptomatic hypoglycemia events and better gastrointestinal tolerability. Three randomised trials of lixisenatide treatment added to basal insulin showed significantly improved glycemic control over placebo, with pronounced postprandial glucose reductions and good tolerability. Discontinuations for adverse events were consistently low, ranging from $2.5 \%$ to $10.4 \%$. As the provision of individualized care moves center stage in diabetes management, lixisenatide with once-daily dosing, a single maintenance dose and fixed-dose pens offers an important treatment option for type 2 diabetes.

Keywords: Clinical trial program; Glucagonlike peptide-1 receptor agonist; Insulin; Lixisenatide; Postprandial glucose; Type 2 diabetes 


\section{INTRODUCTION}

In the last decade, there has been considerable change in the number and type of pharmacotherapies available for type 2 diabetes. One of the most significant advances has been an improved understanding of the incretin effect and its role in the pathophysiology of type 2 diabetes, which has led to the development of a number of new glucose-lowering agents within the incretin class [1]. Both glucagon-like peptide-1 receptor (GLP-1R) agonists and dipeptidyl peptidase-4 (DPP4) inhibitors are now licensed and used routinely in the management of type 2 diabetes [1]. Given the positive impact of GLP-1R agonists on a number of the pathophysiological traits of type 2 diabetes, including clinically significant reductions in body weight, this class of drug continues to expand with new analogs in development [1].

Currently, four GLP-1R agonists-exenatide (both as a twice-daily (BD) and once-weekly (QW) long-acting release (LAR) formulation), liraglutide, and lixisenatide-are available as treatments for type 2 diabetes (Fig. 1). Exenatide is an identical synthetic version of exendin-4, a GLP-1-like peptide isolated from the saliva of the Gila monster lizard Heloderma suspectum that exhibits 53\% amino acid identity with human GLP-1 and is a potent agonist of the human GLP-1R [2]. Exenatide has a terminal half-life of $\sim 2.4 \mathrm{~h}$ and is administered BD subcutaneously [3]. A long-acting release formulation, exenatide-LAR, delivers the drug in microspheres of a biodegradable polymer resulting in a prolonged half-life and allowing once-weekly administration, is also approved [4]. This formulation has been shown to provide better glycemic control than conventional exenatide BD over 52 weeks [5].

Liraglutide is an analog of human GLP-1, modified by a Ser34Arg amino acid substitution
GLP-1 receptor agonists
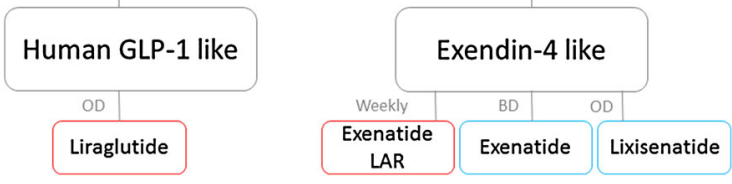

Fig. 1 GLP-1 receptor agonists grouped according to peptide sequence and dosing frequency. GLP-1 receptor agonists grouped as 'GLP-1 like' or 'exendin-4 like' and long-acting (red) or short-acting (blue) with dosing (OD once daily, $B D$ twice daily); $L A R$ long-acting release

and with the addition of a Glu-spaced fatty acid chain through the $\varepsilon$-amino group of Lys at position 26 [1]. These modifications alter the tertiary structure of the molecule, stabilizing liraglutide against DPP-4 degradation and allowing it to self-associate and reversibly bind to serum albumin, creating a circulating reservoir of drug [1]. These changes result in decreased clearance and protracted activity, with a half-life of $13 \mathrm{~h}$ suitable for once-daily (OD) subcutaneous administration [6]. Liraglutide was approved for clinical use in Europe in 2009 and in the USA in 2010.

Lixisenatide (AVE0010) is the fourth GLP-1R agonist to be licensed for the treatment of type 2 diabetes. Like exenatide, the 44-amino acid peptide is based on the structure of exendin-4, with modifications consisting of a deletion of a proline residue and addition of six lysine residues at the $\mathrm{C}$ terminal (Fig. 2) [7]. The in vivo half-life of lixisenatide ( $20 \mu \mathrm{g}$ OD) is $3 \mathrm{~h}$ [8]. Lixisenatide OD is indicated for the treatment of adults with type 2 diabetes to achieve glycemic control in combination with oral glucose-lowering drugs and/or basal insulin when these, together with diet and exercise, do not provide adequate glycemic control.

Although these GLP-1R agonists act through the same receptor, differences in their pharmacokinetics-namely short-acting or 

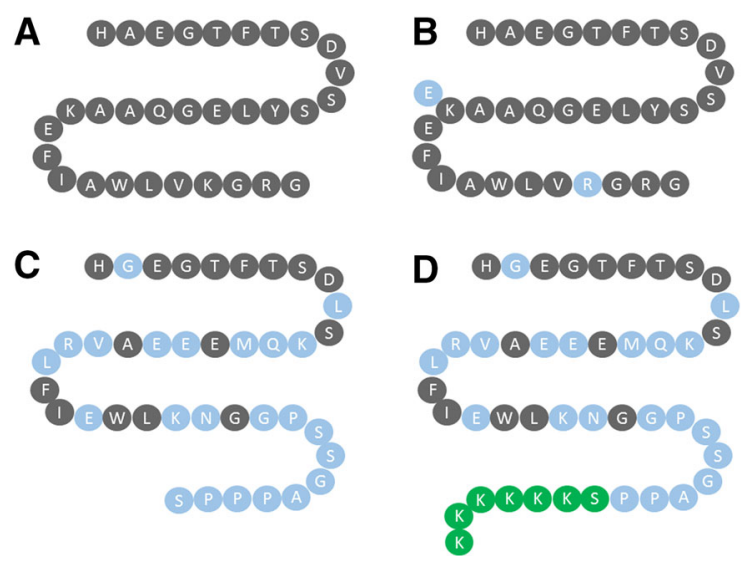

Fig. 2 Peptide sequence of lixisenatide and other GLP-1 receptor agonists. Peptide sequence of native human GLP1 (7-37) (a) and the GLP-1 receptor agonists liraglutide (b), exenatide (c) and lixisenatide (d). Light blue amino acids represent differences to the sequence of human native GLP-1. Green amino acids represent differences to the sequence between exenatide and lixisenatide

long-acting-manifest as distinct physiological profiles, in particular distinct gastric emptying and insulin secretion profiles in the post-meal period [9]. Short-acting agents (exenatide and lixisenatide) induce gastric emptying delay in a similar way to native GLP-1 and blunt postprandial glucose (PPG) excursions. For long-acting agents (e.g., liraglutide), continuous agonism of the GLP-1 receptor results in a desensitization of the gastric emptying effect and, in the postprandial period, the primary glucose-lowering action is mediated by stimulation of insulin secretion and glucagon suppression [9]. This article describes the clinical development program for the use of lixisenatide in the treatment of type 2 diabetes and identifies features of lixisenatide that distinguish it from other GLP-1R agonists.

The analysis in this article is based on previously conducted studies, and does not involve any new studies of human or animal subjects performed by any of the authors.

\section{CLINICAL DEVELOPMENT PROGRAM OF LIXISENATIDE}

\author{
Phase II Dose-Finding Study
}

The dose-response effect of lixisenatide was evaluated in a large group $(n=542)$ of metformin-treated patients with type 2 diabetes using OD or twice-daily (BD) lixisenatide regimens (5-30 $\mu$ g OD or BD) [10]. At inclusion, patients had been treated with metformin monotherapy for $\geq 3$ months but had suboptimal glycemic control (defined as glycated hemoglobin $\left[\mathrm{HbA}_{1 \mathrm{c}}\right] \geq 53 \mathrm{mmol} / \mathrm{mol}$ [7.0\%] and $<75 \mathrm{mmol} / \mathrm{mol}$ [9.0\%]). Patients were randomised to 12 treatment regimens (eight lixisenatide and four volume-matched placebo groups) given OD within $1 \mathrm{~h}$ before breakfast or BD within $1 \mathrm{~h}$ before breakfast and dinner for 13 weeks of treatment. The doses in the 20 and $30 \mu \mathrm{g}$ lixisenatide groups were increased in $5 \mu \mathrm{g} /$ week increments to achieve the treatment dose in weeks $2-4$. The primary endpoint was change in $\mathrm{HbA}_{1 \mathrm{c}}$ from baseline.

The patients enrolled had relatively wellcontrolled diabetes (mean $\mathrm{HbA}_{1 \mathrm{c}}$ of $58 \mathrm{mmol} /$ mol [7.5\%]) with a mean duration of disease of 6.5 years [10]. At week 13, significant, dosedependent reductions in $\mathrm{HbA}_{1 \mathrm{c}}$ (the primary endpoint) were reported [10]. OD and $\mathrm{BD}$ lixisenatide regimens achieved similar $\mathrm{HbA}_{1 \mathrm{c}}$ reductions, with twice-daily dosing failing to provide any relevant additional improvement compared with once-daily regimens. Further increases in dose beyond $20 \mu \mathrm{g}$ OD provided limited benefit relative to the increase in drug exposure that was accompanied by increased gastrointestinal adverse events. This is in keeping with a previous pharmacodynamic study that found lixisenatide $20 \mu \mathrm{g}$ OD and BD significantly improved $\mathrm{HbA}_{1 \mathrm{c}}$ to a similar extent compared with placebo over a 4 -week treatment 
period [8]. In a subgroup of patients, a standardized meal challenge (breakfast) performed at baseline and week 13 showed dose-dependent PPG reductions with all lixisenatide doses [10].

Anti-lixisenatide antibody formation was a relatively frequent phenomenon, detected in the range of $43.1 \%$ (10 $\mu$ g OD group) to $71.2 \%$ (20 $\mu$ g BD group) [10]. No relevant differences were reported in terms of safety and efficacy between the patient populations with antibodypositive and negative status at study end for all dose regimens.

The most frequently reported adverse events were gastrointestinal, primarily nausea, which was dose dependent. Gastrointestinal adverse events generally began during the first 5 weeks of the study and were mild-to-moderate in intensity. There were no cases of pancreatitis. Discontinuations due to treatment-emergent adverse events occurred were low (1.8-11.1\% with OD and $0-14.8 \%$ with BD dosing and $1.8 \%$ of patients receiving placebo) [10].

There was no evidence of a dose-response relationship for symptomatic hypoglycemia (defined as symptoms consistent with hypoglycemia, with an accompanying blood glucose $<3.3 \mathrm{mmol} / \mathrm{L}$ or prompt recovery with carbohydrate), with 1-3 events per treatment group and no episodes of severe hypoglycemia. On the basis of these findings, the $20 \mu \mathrm{g}$ OD dose was chosen for the phase III program because it appeared to offer the best efficacy-totolerability ratio [10].

\section{Phase II Comparison with Liraglutide in Patients Insufficiently Controlled on Metformin}

The pharmacodynamic characteristics of lixisenatide and liraglutide were compared in a head-to-head, open-label phase II trial of 4-week duration [11]. Patients $(N=148)$ with type 2 diabetes with inadequate glycemic control on metformin (median duration of disease of 6.7 years, mean baseline $\mathrm{HbA}_{1 \mathrm{c}} 55-57 \mathrm{mmol} /$ mol [7.2-7.4\%]) were randomised to receive lixisenatide (initiated at $10 \mu \mathrm{g}$ OD for 2 weeks followed by $20 \mu \mathrm{g}$ OD), or liraglutide (started at $0.6 \mathrm{mg}$ and titrated up to $1.8 \mathrm{mg} \mathrm{OD}$ ). The primary outcome, reduction in PPG after a standardized breakfast meal test, was significantly greater with lixisenatide (change from baseline in corrected glucose $\mathrm{AUC}_{0: 30-4: 30 \mathrm{~h}}$ on day 28 was $8.6 \mathrm{~h} \mathrm{mmol} / \mathrm{L}$ greater than liraglutide, $p<0.0001)$. Post-meal insulin secretion was reduced by lixisenatide and increased by liraglutide. Of note, glucagon levels were significantly reduced with lixisenatide over liraglutide $(p<0.05)$. Markers of satiety (obestatin, PYY-36 and oxyntomodulin), which were measured as part of the trial, have not been reported. Both blood pressure and heart rate were recorded. Mean changes in blood pressure were comparable between the two treatment groups. In contrast, heart rate measured on day 29 had decreased (mean of 3.6 beats/min from baseline) with lixisenatide and increased (5.3 beats/min) with liraglutide, which was significantly different [11].

\section{The Phase III Clinical Trial Program}

The Phase III GLP-1 agonist AVE0010 in paTients with type 2 diabetes mellitus for Glycemic cOntrol and sAfety evaLuation (GetGoal) programme included 11 randomised trials designed to examine the efficacy and safety of lixisenatide $20 \mu \mathrm{g}$ OD across the spectrum of patients with type 2 diabetes, including those currently not being treated with anti-diabetic agents, those failing on oral agents and as an adjunct to basal insulin 
therapy (Table 1) [12-22]. The program was largely placebo-controlled, although it included a head-to-head comparison with exenatide (GetGoal-X) [12], and an open-label safety trial of lixisenatide alone conducted for the regulatory authorities in Japan (GetGoalMono-Japan) [13]. In addition, the efficacy and safety profile of lixisenatide in combination with basal insulin was assessed in three randomised trials [14-16]. More than 5,000 patients were recruited in the GetGoal studies worldwide. In three trials, one- or two-step dose increases up to the $20 \mu \mathrm{g}$ OD treatment dose were compared $[13,17,18]$, and in one trial, morning and evening dosing of lixisenatide were compared [19]. In the majority of studies, patients received metformin, reflecting the current recommendation for metformin by NICE and the American Diabetes Association/ European Association for the Study of Diabetes (ADA/EASD) as first-line therapy [23, 24]. Data from the 11 GetGoal trials have been published, or presented at international conferences (summarized in Table 1).

\section{Lixisenatide Monotherapy}

GetGoal-Mono was a 12-week, double-blind, placebo-controlled trial that randomised 361 patients with type 2 diabetes of mean duration 1.1-1.4 years attempting to control their diabetes with diet and exercise alone, to lixisenatide OD for 12 weeks as a one-step dose increase ( $10 \mu \mathrm{g}$ for 2 weeks, then $20 \mu \mathrm{g}$ ) or twostep dose increase ( $10 \mu \mathrm{g}$ for 1 week, $15 \mu \mathrm{g}$ for 1 week, then $20 \mu \mathrm{g}$ ), or placebo also with a oneor two-step increase [17]. $\mathrm{HbA}_{1 \mathrm{c}}$ was improved in both dose escalation groups compared with placebo, with a numerically larger reduction in those with a single-dose increase (least squares mean reduction of $0.66 \%$ with one-step and $0.54 \%$ with two-step, $p<0.0001)$. Significantly, more patients achieved the $\mathrm{HbA}_{1 \mathrm{c}}$ goal of $<7 \%$ with lixisenatide than placebo $(47-52 \%$ vs. $27 \%$, respectively).

A subgroup of 169 patients took a standardized meal test at baseline and week 12; 2-h PPG and 2-h plasma glucose excursions (defined as 2-h PPG minus plasma glucose $30 \mathrm{~min}$ prior to the meal test before study drug administration) were significantly improved compared with placebo [17]. The PPG values were markedly reduced by $4.5-5.5 \mathrm{mmol} / \mathrm{L}$ compared with $0.7 \mathrm{mmol} / \mathrm{L}$ with placebo, and similar reductions in the glucose excursion values were apparent.

Lixisenatide OD was well tolerated; the most frequent adverse events were gastrointestinal (mainly nausea with low rates of vomiting and diarrhea) [17]. The rates of nausea and of discontinuation because of adverse events were similar with the two-step and one-step dose increases. Average body weight reductions of $2 \mathrm{~kg}$ were reported in both lixisenatide and placebo groups, reflecting a marked placebo effect in some patients receiving an inactive injection.

In GetGoal-Mono Japan, Japanese patients experienced a $0.74 \%$ and $0.99 \%$ reduction in $\mathrm{HbA}_{1 \mathrm{c}}$ (one-step or two-step dose increase, respectively) at week 24 , which was sustained at week 76 (reduction of $0.72 \%$ across both groups) from a baseline $\mathrm{HbA}_{1 \mathrm{c}}$ of $66 \mathrm{mmol} / \mathrm{mol}$ (8.2\%). This small, open-label safety study performed for the regulatory authorities in Japan reported nausea as the most commonly reported adverse event, with no new safety signals observed [13].

\section{Patients Inadequately Controlled on Metformin}

GetGoal-M assessed the efficacy and safety of morning or evening injections of lixisenatide in 


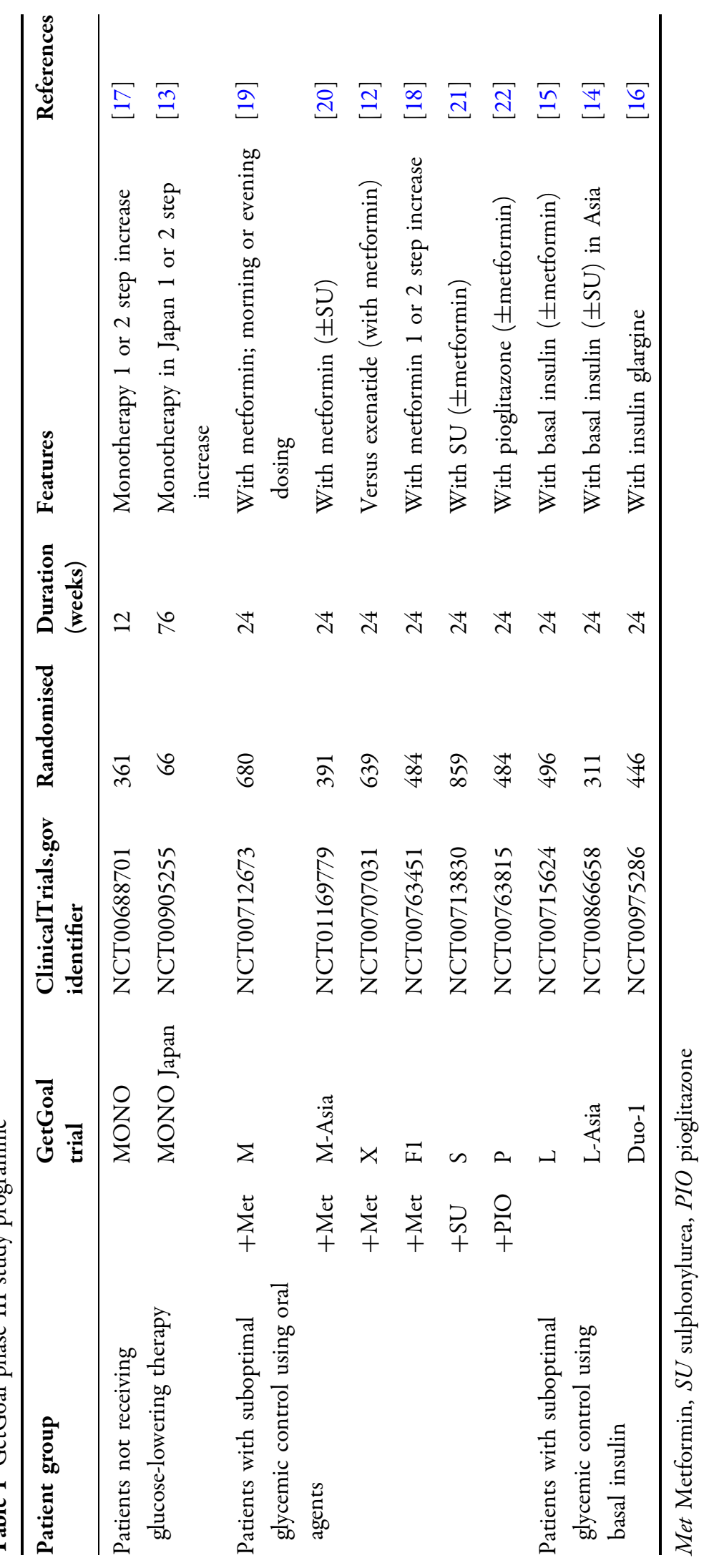


a blinded, placebo-controlled study in patients inadequately controlled on metformin [19]. Lixisenatide OD morning or evening significantly improved glycemic control measured as reduction in $\mathrm{HbA}_{1 \mathrm{c}}$ (reduced by $0.5 \%$ and $0.4 \%$ over placebo, $p<0.0001$, respectively) and proportion achieving target $\mathrm{HbA}_{1 \mathrm{c}}<53 \mathrm{mmol} / \mathrm{mol}$ (7.0\%) (43\% and $40.6 \%$ vs. $22 \%, p<0.0001$, respectively). After a standardized meal test for those receiving morning treatment, lixisenatide had a pronounced effect on 2-h PPG, with a difference of $-4.5 \mathrm{mmol} / \mathrm{L}(p<0.0001)$ over placebo, and on glucose excursion, with a difference of $-3.9 \mathrm{mmol} / \mathrm{L}$ over placebo. GI disturbance was the most common adverse event; nausea and vomiting occurred in $22.7 \%$ and $9.4 \%$ of the morning and $21.2 \%$ and $13.3 \%$ of the evening group, respectively. Symptomatic hypoglycemia was uncommon (2.4\% and $5.1 \%$, respectively) and no severe events were recorded [19].

GetGoal-M-Asia [20], conducted in China, Malaysia, Thailand, and Hong Kong, randomised patients with mean disease duration of $\geq 6.5$ years and baseline $\mathrm{HbA}_{1 \mathrm{c}}$ of 62-63 $\mathrm{mmol} / \mathrm{mol}(7.85-7.95 \%)$ to lixisenatide $20 \mu \mathrm{g}$ OD (one-step dose increase) or placebo [20]. The $\mathrm{HbA}_{1 \mathrm{c}}$ reduction versus placebo at week 24 was $0.36 \% \quad(p=0.0004)$, with a pronounced effect on PPG after a standardized breakfast meal test (lixisenatide associated with a $4.28 \mathrm{mmol} / \mathrm{L}$ reduction compared with placebo $(p<0.0001))$. Nausea and vomiting occurred in $16.3 \%$ and $7.7 \%$ with lixisenatide. There were few cases of symptomatic hypoglycemia [20].

GetGoal-F1 randomised 484 patients with mean diabetes duration of around 6 years inadequately controlled on metformin alone (mean $\mathrm{HbA}_{1 \mathrm{c}}$ of $64 \mathrm{mmol} / \mathrm{mol}$ [8\%]) in a double-blind, placebo-controlled trial with a 24-week treatment period [18], followed by an extension of at least 52 weeks. Patients were randomised to one of four treatment schedules to include a one-step or two-step dose escalation, as per GetGoal-Mono [17].

$\mathrm{HbA}_{1 \mathrm{c}}$ was again improved in both dose escalation groups compared with placebo (least squares mean reduction of $0.5 \%$ [95\% CI $-0.7 \%$ to $-0.3 \%]$ with one-step and $0.4 \%$ [95\% CI $-0.6 \%$ to $-0.2 \%$ ] with two-step, $p<0.0001$ ) [18]. Significantly more patients achieved $\mathrm{HbA}_{1 \mathrm{c}}$ $<53 \mathrm{mmol} / \mathrm{mol}$ (7\%) with lixisenatide than placebo (42.1-47.4\% vs. $24.1 \%$, respectively) at 24 weeks. The efficacy of lixisenatide was maintained during the variable extension period (at week 76: $-0.9 \%$ for one-step, $-0.9 \%$ for two-step and $-0.6 \%$ for combined placebo). The proportion of participants achieving $\mathrm{HbA}_{1 \mathrm{c}}$ targets of $\quad<53 \mathrm{mmol} / \mathrm{mol} \quad(<7 \%)$ and $\leq 48 \mathrm{mmol} / \mathrm{mol} \quad(\leq 6.5 \%)$ were $53.5 \%$ and $34.3 \%$ for lixisenatide one-step, 49.5 and $25.7 \%$ for lixisenatide two-step and $41.8 \%$ and $22.8 \%$ for the combined placebo, respectively. Weight reduction was significantly greater with both lixisenatide 1-step $(-2.6 \mathrm{~kg})$ and 2-step $(-2.7 \mathrm{~kg})$ dose increases than placebo $(-1.6 \mathrm{~kg}$, $p<0.01$ for both comparisons) [18].

At week 24, nausea was the most frequent adverse event (26.1-35.4\%). Symptomatic hypoglycemia (defined as symptoms consistent with hypoglycemia, with an accompanying blood glucose $<3.3 \mathrm{mmol} / \mathrm{L}$ or prompt recovery with carbohydrate) occurred infrequently in all arms of the study $(\leq 2.5 \%)$; no severe hypoglycemic events were reported. In the extension study, the most frequently reported AEs were nausea and vomiting, with few discontinuations. Symptomatic hypoglycemia remained uncommon (3.7-7.5\%), with a similar proportion of patients with events in the placebo arm (7.5\%). These findings suggested that the 
one-step dose increase was appropriate for treatment initiation [18].

In the open-label GetGoal-X study, 639 patients with type 2 diabetes inadequately controlled with metformin were randomised to lixisenatide $20 \mu \mathrm{g}$ OD or exenatide $10 \mu \mathrm{g}$ BD. Five patients were excluded and the analysis population comprised lixisenatide $20 \mu \mathrm{g}$ OD $(n=318)$ or exenatide $10 \mu \mathrm{g} \mathrm{BD}(n=316)$, with a main 24-week treatment period followed by an extension of at least 52 weeks [12]. Lixisenatide achieved the primary endpoint of noninferiority to exenatide for the reduction in $\mathrm{HbA}_{1 \mathrm{c}}$ from baseline; the least squares (LS) mean $\pm \mathrm{SE}$ change from baseline with lixisenatide was $-0.79 \% \pm 0.05$ and $-0.96 \%$ \pm 0.05 with exenatide (LS mean difference, 0.17\%; 95\% CI, 0.033-0.297\%). This fulfilled the pre-specified non-inferiority criterion based on the upper CI limit of $\leq 0.4 \%$; the stricter CI margin of $0.3 \%$ more recently recommended by the European Medicines Agency (EMA) was met in the modified intention-to-treat population. Improvements in mean FPG and the proportions of patients achieving $\mathrm{HbA}_{1 \mathrm{c}}<53 \mathrm{mmol} / \mathrm{mol}(7 \%)$ were similar between the treatments. Both treatments were associated with body-weight reductions-LS mean \pm SE change from baseline with lixisenatide OD was $-2.96 \pm 0.23$ and $-3.98 \pm 0.23 \mathrm{~kg}$ with exenatide BD.

The overall incidence of adverse events was similar between the two treatments, but with numerically fewer adverse events leading to discontinuation with lixisenatide $(10.4 \%$ vs. $13.0 \%$ with exenatide), and fewer premature discontinuations overall with lixisenatide $(12.9 \%$ vs. $14.2 \%$ with exenatide). The incidence of nausea was lower in patients receiving lixisenatide $O D$ than in those who received exenatide twice per day $(24.5 \%$ vs. $35.1 \%$, respectively, $p<0.05$ ). Fewer patients experienced episodes of symptomatic

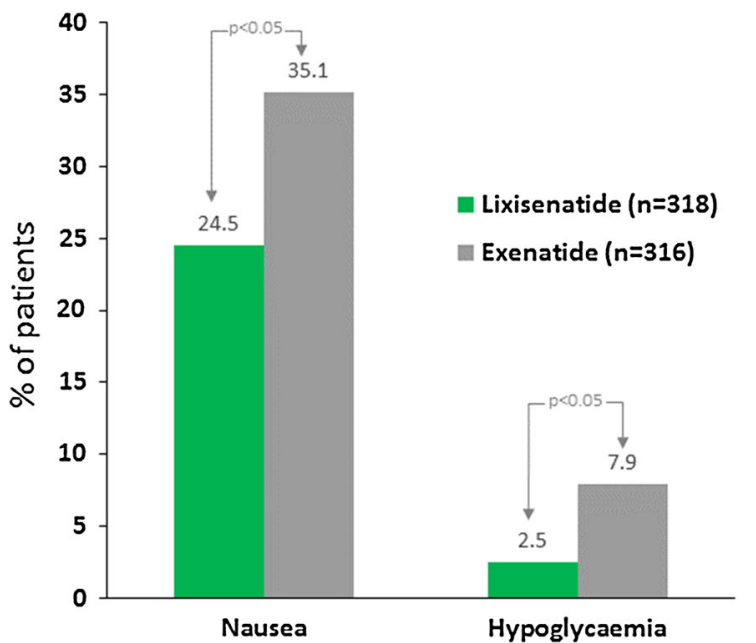

Fig. 3 In the GetGoal-X study, patients experienced a reduced incidence of nausea and a lower proportion of patients experienced hypoglycemia with lixisenatide OD versus exenatide $\mathrm{BD}[12]$

hypoglycemia with lixisenatide than exenatide (2.5\% vs. $7.9 \% ; p<0.05$; Fig. 3$)$. This study demonstrated that lixisenatide was noninferior to exenatide in improving glycemic control in patients with type 2 diabetes insufficiently controlled on metformin, but may result in fewer hypoglycemic episodes and have a more favorable GI tolerability profile [12].

\section{Patients Inadequately Controlled on Sulphonylurea (SU)}

GetGoal-S randomised 859 patients with longer duration diabetes (mean duration of 8.0-8.5 years) who were inadequately controlled on an SU (85\% were receiving metformin in addition to their SU therapy at baseline) to lixisenatide $20 \mu \mathrm{g}$ OD or placebo for 24 weeks, with an optional extension of 52 weeks [21]. Of note, the study enrolled a different ethnic mix to most other GetGoal studies with $45 \%$ of patients being of Asian origin. 
Lixisenatide significantly reduced $\mathrm{HbA}_{1 \mathrm{c}}$ compared with placebo $(-0.85 \%$ vs. $-0.10 \%$; $p<0.0001)$ at 24 weeks; it also significantly improved 2-h PPG, FPG, body weight and the proportion of patients achieving $\mathrm{HbA}_{1 \mathrm{c}}$ $<53 \mathrm{mmol} / \mathrm{mol}$ (7\%) compared with placebo. Higher rates of nausea and vomiting with lixisenatide were recorded compared with placebo. Symptomatic hypoglycemia was not different between lixisenatide and placebo (15.3\% vs. $12.3 \% ; p=\mathrm{NS})$ [21].

\section{Patients Inadequately Controlled on Thiazolidinediones}

GetGoal-P assessed the addition of lixisenatide to therapy in patients inadequately controlled on $\geq 30 \mathrm{mg} /$ day of pioglitazone (with or without metformin) [22]. A total of 484 patients with a mean duration of diabetes of 8.1 years were randomised to receive lixisenatide $20 \mu \mathrm{g}$ OD $(n=323)$ or placebo $(n=161)$ with a two-step dose increase, in combination with pioglitazone, for the main double-blind treatment period of 24 weeks, followed by a variable double-blind extension of at least 52 weeks. Around $81 \%$ of patients were using metformin at screening.

Lixisenatide significantly reduced $\mathrm{HbA}_{1 \mathrm{c}}$ from baseline to week 24 compared with placebo (LS mean reduction of $-0.90 \%$ vs. $-0.34 \% ; p<0.0001)$ and significantly greater proportions of patients receiving lixisenatide achieved $\mathrm{HbA}_{1 \mathrm{c}}$ goals of $\leq 48 \mathrm{mmol} / \mathrm{mol}(6.5 \%)$ and $<53 \mathrm{mmol} / \mathrm{mol}$ (7.0\%) compared with placebo [22]. Efficacy was maintained in the extension period $\left(\mathrm{HbA}_{1 \mathrm{c}}\right.$ reduced by $1.1 \%$ (lixisenatide) and $0.6 \%$ (placebo) at week 76). Lixisenatide significantly improved FPG levels. There was no significant reduction in body weight compared with placebo. Significantly fewer lixisenatide-treated patients required rescue therapy compared with placebo-treated patients. Lixisenatide was well tolerated with similar rates of symptomatic hypoglycemia in both groups $(3.4 \%$ with lixisenatide vs. $1.2 \%$ with placebo) [22]. This study demonstrated that the addition of lixisenatide to pioglitazone therapy significantly improved glycemic control with a low risk of hypoglycemia and good tolerability.

\section{Patients Inadequately Controlled on Basal Insulin}

GetGoal-L-Asia randomised 311 patients with long-duration diabetes (mean 13.9 years) who were inadequately controlled on basal insulin to lixisenatide $20 \mu \mathrm{g}$ OD $(n=154)$, or placebo $(n=157)$ for 24 weeks [14]. All patients continued treatment throughout the study with their established doses of basal insulin with or without SU. Approximately $70 \%$ of patients were receiving an $\mathrm{SU}$ at screening. Around $60 \%$ of patients were receiving insulin glargine, $27 \%$ were receiving insulin detemir and $13 \%$ were receiving NPH insulin [14]. This study was conducted in Japan, South Korea, Taiwan and the Philippines, where patients with type 2 diabetes have a number of distinct features, including a relatively low body mass index (BMI) (in this study a mean of $25.3 \mathrm{~kg} / \mathrm{m}^{2}$ ) and tend to have reduced $\beta$ cell function compared with Western subjects.

Lixisenatide significantly improved $\mathrm{HbA}_{1 \mathrm{c}}$ levels compared with placebo by 24 weeks (LS mean reduction of $-0.88 \%, 95 \%$ CI -1.116 , $-0.650 ; p<0.0001)$ and significantly more patients achieved $\mathrm{HbA}_{1 \mathrm{c}}$ targets with lixisenatide than placebo [14]. Their long duration of diabetes suggests that these patients would have minimal insulin secretion capacity remaining and, therefore, it will be of 
interest to see the glycemic reductions stratified by duration, with the expectation that those with shorter duration will experience better glycemic improvement. Lixisenatide significantly improved 2-h PPG levels, reduced glucose excursions and 7-point self-measured plasma glucose (SMPG) levels compared with placebo, as well as significantly improving FPG and lowering the daily insulin requirement. The PPG reduction apparent after breakfast was extremely marked (LS mean difference of $-7.83 \mathrm{mmol} / \mathrm{L})$. There was a small but significantly greater reduction in daily basal insulin dose with lixisenatide than placebo $(-1.39 \pm 0.46$ vs $-0.11 \pm 0.44 \mathrm{U}, p=0.0019)$. Discontinuation due to adverse events was higher with lixisenatide than placebo $(9.1 \%$ vs. $3.2 \%$, respectively), as was symptomatic hypoglycemia $(42.9 \%$ vs. $23.6 \%)$ although there was no difference compared with placebo in those patients not receiving SU (32.6\% with lixisenatide vs. $28.3 \%$ with placebo). There were no cases of severe hypoglycemia [14].

GetGoal-L randomised 496 patients inadequately controlled on basal insulin and metformin to lixisenatide $20 \mu \mathrm{g}$ OD or placebo for 24 weeks with a double-blind extension of at least 52 weeks [15]. Patients were randomised in a 2:1 ratio to lixisenatide $(n=329)$ or placebo $(n=167)$. The mean duration of diabetes was approximately 12.5 years, and $79 \%$ of patients were using metformin at screening. Patients had been receiving basal insulin for 3.1 years on average, with 50\% taking insulin glargine and the majority of the remainder taking $\mathrm{NPH}$ insulin.

Addition of lixisenatide to basal insulin resulted in significant improvements in glycemic control compared with placebo, with an LS mean $\mathrm{HbA}_{1 \mathrm{c}}$ reduction of $-0.4 \%$ (95\% CI $-0.6,-0.2 ; p=0.0002)$ [15]. Significantly, more lixisenatide-treated patients achieved $\mathrm{HbA}_{1 \mathrm{c}}$ goals than placebo-treated patients. There were significant improvements in 2 -h post-breakfast PPG (LS mean difference of $-3.8 \mathrm{mmol} / \mathrm{L} ; 95 \%$ CI $-4.7,-2.9 ; p<0.0001)$, 2-h post-breakfast glucose increment and average 7-point SMPG with lixisenatide compared with placebo. Patients receiving lixisenatide lost an average of $1.3 \mathrm{~kg}$ of weight compared with those receiving placebo $(p<0.0001)$. Dose change of basal insulin by week 24 was greater with lixisenatide than placebo ( -5.6 vs. -1.9 units/ day, LS mean change -3.7 units/day; $p=0.012$ ). There was a non-significant increase in the incidence of symptomatic hypoglycemia in patients treated with lixisenatide compared with placebo $(26.5 \%$ vs. $21.0 \%)$. There was a low rate of discontinuation due to adverse events with lixisenatide of $(7.6 \%$ vs. $4.8 \%$ with placebo). These results demonstrated the feasibility of adding a GLP$1 \mathrm{R}$ agonist to those mainly North American and Western European patients not achieving target glycemic control on insulin [15].

In GetGoal-Duo-1, patients with inadequate glycemic control on metformin (average $\mathrm{HbA}_{1 \mathrm{c}}$ of $70 \mathrm{mmol} / \mathrm{mol}$ [8.6\%]) were initiated and optimized on insulin glargine by titration to a target FPG range of $4.4-5.6 \mathrm{mmol} / \mathrm{L}$ over a 12-week period (study design shown in Fig. 4) [16]. Patients not achieving target $\mathrm{HbA}_{1 \mathrm{c}}$ of $53 \mathrm{mmol} / \mathrm{mol}(7 \%)$ and with SMPG $\leq 7.8 \mathrm{mmol} /$ $\mathrm{L}(n=446)$ were randomised to lixisenatide OD or placebo; both insulin glargine and metformin were continued. SU therapy was stopped at randomisation, and $12 \%$ of patients were receiving a thiazolidinedione (TZD). Patients had a mean duration of diabetes of 9.2 years.

The lixisenatide group experienced a significant improvement in glycemic control compared with placebo, with an LS mean 


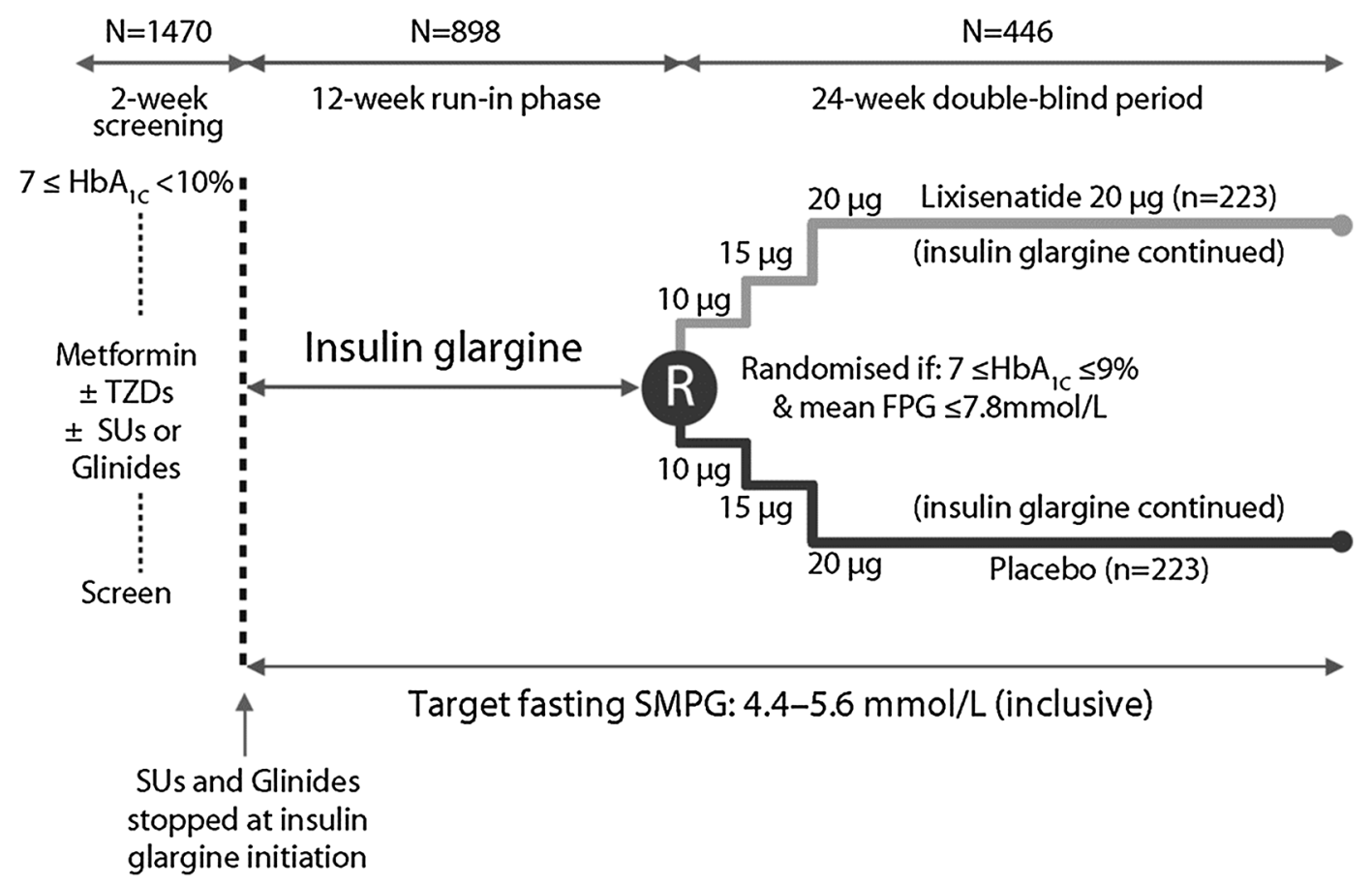

Fig. 4 Study design of GetGoal-Duo-1 [16]. FPG Fasting plasma glucose, $T Z D$ thiazolidinedione, $S U$ sulphonylurea

difference of $-0.3 \% \quad(p<0.0001)$ between lixisenatide and placebo and more lixisenatide patients achieved target glycemic control (56\% vs. $39 \%, p=0.0001)$ [16]. Addition of lixisenatide to insulin significantly improved 2-h PPG (mean reduction of $-3.2 \mathrm{mmol} / \mathrm{L}$ vs. placebo, $p<0.0001)$, and resulted in a mean difference in body weight of $-0.9 \mathrm{~kg}$ compared with placebo $(p=0.0012)$. Insulin glargine dose increased more in the placebo group $(+3.1$ units per day and +5.3 units for lixisenatide and placebo groups, respectively, $p=0.03$ ). The most common adverse events were mild and transient nausea and vomiting. Symptomatic hypoglycemia occurred in $22.4 \%$ of the lixisenatide-treated patients and $13.5 \%$ of those receiving placebo [16].

\section{Cardiovascular Outcome Trial}

A large, cardiovascular outcomes' study (The Evaluation of LIXisenatide in Acute coronary syndrome (ELIXA) study is ongoing [25], and complies with US Food and Drug Administration (FDA) guidance that requires pharmaceutical manufacturers to demonstrate that new drugs for type 2 diabetes do not increase the risk of cardiovascular events [26]. Although the FDA has no requirement for the investigational drug to show superiority to placebo, ELIXA is designed to demonstrate that lixisenatide reduces cardiovascular morbidity and mortality in patients with type 2 diabetes who have recently experienced an acute coronary syndrome event. Patients have been randomised, double-blind, to receive lixisenatide $20 \mu \mathrm{g}$ OD or placebo. This eventdriven study has an estimated enrollment of 6,000 patients and will run until the last patient has been followed up for at least 10 months; the median follow-up is estimated to be nearly 2 years. The primary endpoint is the time to the first occurrence of a primary cardiovascular event (the composite of cardiovascular death, 
non-fatal myocardial infarction, non-fatal stroke and hospitalization for unstable angina). The study is one of four cardiovascular outcomes' studies ongoing with GLP-1R agonists; ELIXA is expected to be reported in 2014/2015 [27].

\section{DISCUSSION}

To date, the clinical development program suggests that lixisenatide has an appropriate pharmacodynamic action, with reductions in blood glucose, in particular marked reductions in PPG, manifesting as improvements in glycemic control, a beneficial effect on body weight, and with limited risk of hypoglycemia with $20 \mu \mathrm{g}$ OD dosing.

Reductions in $\mathrm{HbA}_{1 \mathrm{c}}$ with lixisenatide from baseline were consistent across the GetGoal programme, with the main efficacy outcome met in all studies. The reductions from baseline in $\mathrm{HbA}_{1 \mathrm{c}}$ ranged from $-0.7 \%$ to $-1.0 \%$ (Table 2). These reductions appear slightly lower than those reported with liraglutide, which may reflect differences in baseline characteristics, including $\mathrm{HbA}_{1 \mathrm{c}}$, or differences in pharmacodynamics such as the more pronounced effect that long-acting GLP-1R agonists exert on FPG [9]; however, it is difficult to make indirect comparisons across studies. The randomised comparison of lixisenatide $\mathrm{OD}$ with exenatide $\mathrm{BD}$ showed lixisenatide was non-inferior to exenatide and with similar numbers of patients achieving target $\mathrm{HbA}_{1 \mathrm{c}}$ of $53 \mathrm{mmol} / \mathrm{mol}$ (7\%) (around a half in each treatment group) [12], but this was achieved with threefold fewer symptomatic hypoglycemic events and with better gastrointestinal tolerability than exenatide BD. Discontinuations for adverse events were consistently low, ranging from $2.5 \%$ to $10.4 \%$ across the program (Table 3 ).

Except for GetGoal-Mono Japan, the GetGoal studies were 12-24 weeks in duration with longer, safety-orientated study extensions of at least 1 year planned in six trials (GetGoalF1, -M, -X, -S, -P and -L). Long-term efficacy data reported so far (from GetGoal-P and GetGoalF1) suggest that the glycemic improvement with lixisenatide is maintained, with good tolerability during long-term treatment and no increased hypoglycemia risk versus placebo [18, 22].

Lixisenatide treatment had a consistent, pronounced effect on PPG [14-18, 21], reflecting the rapid increase in plasma levels after injection that leads to delayed gastric emptying and delayed systemic glucose absorption, which manifest as blunted postmeal glucose excursions [9]. Long-acting GLP$1 \mathrm{R}$ agonists do not reduce PPG to the same extent and do not exert the same effect on gastric motility after long-term use as shortacting agonists [9]. Studies of gastric emptying suggest that long-acting agonists are subject to desensitization/tachyphylaxis of the effect, whereas short-acting agonists such as lixisenatide continue to inhibit gastric emptying even after repeated dosing [9]. The pharmacodynamic differences with liraglutide were shown in the phase II comparison, in which lixisenatide OD had a significantly greater PPG-lowering effect than liraglutide OD after a standardized breakfast test in patients with type 2 diabetes [11]. This was associated with greater reductions in postprandial insulin secretion than liraglutide, which is consistent with slowing of gastric emptying. In addition, lixisenatide markedly and significantly suppressed glucagon secretion compared to liraglutide. 
Table 2 Glycemic control and weight change in the GetGoal phase III study programme

\begin{tabular}{|c|c|c|c|c|c|c|c|c|}
\hline Study & $\begin{array}{l}\text { Background } \\
\text { treatment }\end{array}$ & $\begin{array}{l}\text { Study } \\
\text { design }\end{array}$ & $\begin{array}{l}\text { Duration } \\
\text { (weeks) }\end{array}$ & $\begin{array}{l}\text { Patients }^{\mathbf{a}} \\
(N)\end{array}$ & Dosing $^{b}$ & $\begin{array}{l}\text { Baseline } \\
\text { HbA }_{1 c} \\
(\%)\end{array}$ & $\begin{array}{l}\Delta \\
\mathbf{H b A}_{1 \mathrm{c}}\end{array}$ & $\begin{array}{l}\Delta \\
\text { Weight } \\
(\mathbf{k g})\end{array}$ \\
\hline \multirow{3}{*}{$\begin{array}{l}\text { GetGoal-Mono } \\
{[17]}\end{array}$} & \multirow[t]{3}{*}{ None } & \multirow{3}{*}{$\begin{array}{l}\mathrm{R}, \mathrm{DB} \\
\mathrm{PC}\end{array}$} & \multirow[t]{3}{*}{12} & \multirow[t]{3}{*}{361} & 1 & 8.1 & -0.9 & -2.0 \\
\hline & & & & & 2 & 8.0 & -0.7 & -2.0 \\
\hline & & & & & $\mathrm{PBO}$ & 8.1 & -0.2 & -1.6 \\
\hline \multirow{2}{*}{$\begin{array}{l}\text { GetGoal-Mono } \\
\text { Japan [13] }\end{array}$} & \multirow[t]{2}{*}{ None } & \multirow[t]{2}{*}{$\mathrm{R}, \mathrm{OL}$} & \multirow[t]{2}{*}{24} & \multirow[t]{2}{*}{69} & 1 & 8.2 & -0.7 & -0.4 \\
\hline & & & & & 2 & 8.2 & -1.0 & -1.1 \\
\hline \multirow[t]{3}{*}{ GetGoal-M [19] } & \multirow[t]{3}{*}{ Metformin } & \multirow{3}{*}{$\begin{array}{l}\mathrm{R}, \mathrm{DB} \\
\mathrm{PC}\end{array}$} & \multirow[t]{3}{*}{24} & \multirow[t]{3}{*}{680} & $\mathrm{AM}$ & 8.0 & -0.9 & -2.0 \\
\hline & & & & & PM & 8.1 & -0.8 & -2.0 \\
\hline & & & & & $\mathrm{PBO}$ & 8.1 & -0.4 & -1.6 \\
\hline \multirow{2}{*}{$\begin{array}{l}\text { GetGoal-M-Asia } \\
{[20]}\end{array}$} & \multirow[t]{2}{*}{ Metformin $\pm S U$} & \multirow{2}{*}{$\begin{array}{l}\mathrm{R}, \mathrm{DB} \\
\mathrm{PC}\end{array}$} & \multirow[t]{2}{*}{24} & \multirow[t]{2}{*}{391} & 1 & 8.0 & -0.8 & -1.5 \\
\hline & & & & & $\mathrm{PBO}$ & 7.9 & -0.5 & -1.2 \\
\hline \multirow[t]{3}{*}{ GetGoal-F1 [18] } & \multirow[t]{3}{*}{ Metformin } & \multirow{3}{*}{$\begin{array}{l}\mathrm{R}, \mathrm{DB}, \\
\mathrm{PC}\end{array}$} & \multirow[t]{3}{*}{24} & \multirow[t]{3}{*}{482} & 1 & 8.0 & -0.9 & -2.6 \\
\hline & & & & & 2 & 8.1 & -0.8 & -2.7 \\
\hline & & & & & $\mathrm{PBO}$ & 8.0 & -0.4 & -1.6 \\
\hline \multirow[t]{2}{*}{ GetGoal-X [12] } & \multirow[t]{2}{*}{ Metformin } & \multirow{2}{*}{$\begin{array}{l}\mathrm{R}, \mathrm{OL} \\
\mathrm{CC}\end{array}$} & \multirow[t]{2}{*}{24} & \multirow[t]{2}{*}{634} & 2 & 8.0 & -0.8 & -3.0 \\
\hline & & & & & EXE & 8.0 & -1.0 & -4.0 \\
\hline \multirow[t]{2}{*}{ GetGoal-S [21] } & \multirow{2}{*}{$\mathrm{SU} \pm$ metformin } & $\mathrm{R}, \mathrm{DB}$ & 24 & 859 & 2 & 8.3 & -0.9 & -1.8 \\
\hline & & PC & & & $\mathrm{PBO}$ & 8.2 & -0.1 & -0.9 \\
\hline GetGoal-P [22] & $\mathrm{PIO} \pm$ metformin & $\mathrm{R}, \mathrm{DB}$ & 24 & 484 & 2 & 8.1 & -0.9 & -0.2 \\
\hline & & PC & & & $\mathrm{PBO}$ & 8.1 & -0.3 & +0.2 \\
\hline GetGoal-L [15] & Insulin \pm metformin & $\mathrm{R}, \mathrm{DB}$ & 24 & 496 & 2 & 8.4 & -0.7 & -1.8 \\
\hline & & PC & & & PBO & 8.4 & -0.4 & -0.5 \\
\hline GetGoal-L-Asia & Insulin $\pm S U$ & $\mathrm{R}, \mathrm{DB}$ & 24 & 311 & 2 & 8.5 & -0.8 & -0.4 \\
\hline$[14]$ & & PC & & & $\mathrm{PBO}$ & 8.5 & +0.1 & +0.1 \\
\hline GetGoal-Duo-1 & Insulin \pm metformin & $\mathrm{R}, \mathrm{DB}$ & 24 & 446 & 2 & 7.6 & -0.7 & +0.3 \\
\hline$[16]$ & $\pm S U \pm T Z D$ & PC & & & $\mathrm{PBO}$ & 7.6 & -0.4 & +1.2 \\
\hline
\end{tabular}

$\Delta$ is from baseline to study end

$A M$ Morning, $C C$ comparator controlled, $D B$ double-blind, $E X E$ exenatide, $O L$ open-label, $P B O$ placebo, $P C$ placebocontrolled, $P I O$ pioglitazone, $P M$ evening, $R$ randomised, $S U$ sulphonylurea, $T Z D$ thiazolidinedione, $E X E$ exenatide $10 \mu \mathrm{g}$ twice daily

a Analysis population

b Dosing: 1, one-step dose increase; 2, two-step dose increase; AM or PM dosing; pooled placebo values 
Table 3 Incidence of selected gastrointestinal adverse events during the GetGoal phase III study programme

\begin{tabular}{|c|c|c|c|c|}
\hline Study & Dosing $^{a}$ & Nausea (\%) & Vomiting (\%) & Discontinuations $^{\mathbf{b}}(\%)$ \\
\hline \multirow[t]{3}{*}{ GetGoal-Mono [17] } & 1 & 20.2 & 6.7 & 2.5 \\
\hline & 2 & 24.2 & 7.5 & 4.2 \\
\hline & $\mathrm{PBO}$ & 4.1 & 0 & 0.8 \\
\hline \multirow[t]{2}{*}{ GetGoal-Mono Japan [13] } & 1 & 50.0 & 2.8 & 11.1 \\
\hline & 2 & 36.4 & 12.1 & 9.1 \\
\hline \multirow[t]{3}{*}{ GetGoal-M [19] } & $\mathrm{AM}$ & 22.7 & 9.4 & 7.1 \\
\hline & PM & 21.2 & 13.3 & 5.5 \\
\hline & $\mathrm{PBO}$ & 7.6 & 2.9 & 1.2 \\
\hline \multirow[t]{2}{*}{ GetGoal-M-Asia [20] } & 1 & 16.3 & 7.7 & 8.7 \\
\hline & $\mathrm{PBO}$ & 2.6 & 1.0 & 5.1 \\
\hline \multirow[t]{3}{*}{ GetGoal-F1 [18] } & 1 & 26.1 & 11.8 & 5.6 \\
\hline & 2 & 35.4 & 15.5 & 8.1 \\
\hline & $\mathrm{PBO}$ & 4.4 & 0 & 2.5 \\
\hline \multirow[t]{2}{*}{ GetGoal-X [12] } & 2 & 24.5 & 10.1 & 10.4 \\
\hline & EXE & 35.1 & 13.3 & 13.0 \\
\hline \multirow[t]{2}{*}{ GetGoal-S [21] } & 2 & 25.3 & 8.7 & 9.8 \\
\hline & $\mathrm{PBO}$ & 7.0 & 3.5 & 4.9 \\
\hline \multirow[t]{2}{*}{ GetGoal-P [22] } & 2 & 23.5 & 6.8 & 6.5 \\
\hline & $\mathrm{PBO}$ & 10.6 & 3.7 & 5.0 \\
\hline \multirow[t]{2}{*}{ GetGoal-L [15] } & 2 & 26.2 & 8.2 & 7.6 \\
\hline & $\mathrm{PBO}$ & 8.4 & 0.6 & 4.8 \\
\hline \multirow[t]{2}{*}{ GetGoal-L-Asia [14] } & 2 & 39.6 & 18.2 & 9.1 \\
\hline & $\mathrm{PBO}$ & 4.5 & 1.9 & 3.2 \\
\hline \multirow[t]{2}{*}{ GetGoal-Duo-1 [16] } & 2 & 27.4 & 9.4 & 8.5 \\
\hline & $\mathrm{PBO}$ & 4.9 & 1.3 & 3.6 \\
\hline
\end{tabular}

$A M$ Morning or $P M$ evening, $P B O$ pooled placebo values, EXE exenatide (10 $\mu \mathrm{g}$ twice daily)

a Dosing: one-step dose increase; two-step dose increase

${ }^{b}$ Due to treatment-emergent adverse events

There is an increased interest in addressing the glycemic needs of patients not achieving target despite basal insulin therapy. Traditionally, postprandial hyperglycemic excursions have been addressed by initiating rapid-acting insulin at mealtimes. This insulin intensification requires additional plasma glucose monitoring and is frequently associated with body weight gain and a risk of hypoglycemia. The three studies with 
lixisenatide have described the efficacy and safety profile of lixisenatide add-on to basal insulin in more than 1,200 patients, and have demonstrated that lixisenatide offers a treatment option that may be particularly suited to these patients [14-16]. Lixisenatide lowered $\mathrm{HbA}_{1 \mathrm{c}}$ with beneficial effects on body weight and minimal hypoglycemic risk. EASD and ADA guidelines support this approach of the addition of a GLP-1R agonist to basal insulin, when necessary [24].

Antibody formation was expected in the studies, as has been found in studies of exenatide [27]. In the GetGoal-Mono study, $56-60 \%$ of patients developed anti-lixisenatide antibodies, with no apparent effect on efficacy or safety [17]. This proportion of antibodypositive patients is roughly similar to that shown in studies with exenatide BD and QW [28], suggesting that antibody formation with lixisenatide is unlikely to impact on efficacy or safety outcomes.

In addition to its efficacy, lixisenatide has a number of properties which improve its ease of use. Lixisenatide has a simple one-step dose increase and a single maintenance dose of $20 \mu \mathrm{g}$ OD for all patients. This dosing regimen is simplified further with two fixed-dose pens, each supplying 14 doses. The $10 \mu \mathrm{g}$ pen is used for 2 weeks for the initiation phase, and the $20 \mu \mathrm{g}$ pen is used for the maintenance dose thereafter.

A fixed-ratio combination of lixisenatide and insulin glargine is under development ('LixiLan'). The phase III program comprises two studies, LixiLan-O and LixiLan- $\mathrm{L}$, and is planned to enroll more than 1,800 patients with inadequate glycemic control on oral antidiabetic drugs or not at target on basal insulin [29]. The OD dosing delivered in a single pen may offer an attractive treatment escalation pathway for patients with inadequate glycemic control. Lixisenatide offers an important addon option to patients as the diabetes treatment paradigm moves to individualizing patient care [24].

The ELIXA trial is ongoing and may be the first GLP-1 cardiovascular outcomes' study to report [25]. The effects of GLP-1R agonists beyond their glucose-lowering activity are numerous, and include changes in blood pressure, endothelial function, body weight, cardiac metabolism, lipid metabolism, left ventricular function, atherosclerosis, and the response to ischemia-reperfusion injury [25]. The findings of ELIXA, if they confirmed cardiovascular protection, may open a new avenue for cardiovascular risk reduction in type 2 diabetes.

\section{CONCLUSION}

Lixisenatide is the latest addition to the GLP-1R agonist class of treatments for type 2 diabetes. Although the fourth agent to be licensed, its distinct pharmacodynamic action with marked effects on PPG supports the effective glycemic management of patients with inadequate control on basal insulin, an approach that has been validated in three phase III clinical trials. This, coupled with patient-centric propertiesonce-daily dosing, a one-step increase to a single maintenance dose, and a lower acquisition cost-suggest lixisenatide is an important additional treatment option in type 2 diabetes.

\section{ACKNOWLEDGMENTS}

Professor Stephen Bain had full access to all of the data in this study and takes complete responsibility for the integrity of the data and accuracy of the data analysis. Medical writing 
assistance for this study was provided by Aidan McManus, PhD CMPP of Edge Medical Communications, Dorking, UK, funded by Sanofi, Guildford, UK. Article processing charges for this article were funded by Sanofi. Professor Stephen Bain meets the ICMJE criteria for authorship for this manuscript, takes responsibility for the integrity of the work as a whole, and has given final approval for the version to be published.

\section{Conflict of interest. Professor Bain has acted} as an advisor and speaker on behalf of the following companies which market medicines which act on the incretin system: Novo Nordisk, Eli Lilly, MSD, Novartis, BMS and Sanofi.

Compliance with ethics guidelines. The analysis in this article is based on previously conducted studies, and does not involve any new studies of human or animal subjects performed by any of the authors.

Open Access. This article is distributed under the terms of the Creative Commons Attribution Noncommercial License which permits any noncommercial use, distribution, and reproduction in any medium, provided the original author(s) and the source are credited.

\section{REFERENCES}

1. Lovshin JA, Drucker DJ. Incretin-based therapies for type 2 diabetes mellitus. Nat Rev Endocrinol. 2009;5:262-9.

2. Kolterman OG, Buse JB, Fineman MS, et al. Synthetic exendin-4 (exenatide) significantly reduces postprandial and fasting plasma glucose in subjects with type 2 diabetes. J Clin Endocrinol Metab. 2003;88:3082-9.

3. Bray GM. Exenatide. Am J Health Syst Pharm. 2006;63:411-8.
4. Russell-Jones D, Gough S. Recent advances in incretin-based therapies. Clin Endocrinol. 2012;77:489-99.

5. Buse JB, Drucker DJ, Taylor KL, et al. DURATION-1: exenatide once weekly produces sustained glycemic control and weight loss over 52 weeks. Diabetes Care. 2010;33:1255-61.

6. Raskin P, Mora PF. Glycaemic control with liraglutide: the phase 3 trial programme. Int J Clin Pract Suppl. 2010;64(Suppl. 167):21-7.

7. Werner U, Haschke G, Herling AW, et al. Pharmacological profile of lixisenatide: a new GLP-1 receptor agonist for the treatment of type 2 diabetes. Regul Pept. 2010;164:58-64.

8. Distiller L, Ruus P. Pharmacokinetics and pharmacodynamics of GLP-1 agonist AVE0010 in type 2 diabetes patients. Diabetes. 2008;57(Suppl. 1):Abstract 520-P.

9. Meier JJ. GLP-1 receptor agonists for individualized treatment of type 2 diabetes mellitus. Nat Rev Endocrinol. 2012;8:728-42.

10. Ratner RE, Rosenstock J, Boka G, et al. Dosedependent effects of the once-daily GLP-1 receptor agonist lixisenatide in patients with Type 2 diabetes inadequately controlled with metformin: a randomized, double-blind, placebo-controlled trial. Diabet Med. 2010;27:1024-32.

11. Kapitza C, Forst $\mathrm{T}$, Coester $\mathrm{HV}$, et al. Pharmacodynamic characteristics of lixisenatide once daily versus liraglutide once daily in patients with type 2 diabetes insufficiently controlled on metformin. Diabetes Obes Metab. 2013;15:642-9.

12. Rosenstock J, Raccah D, Koranyi L, et al. Efficacy and safety of lixisenatide once daily versus exenatide twice daily in type 2 diabetes inadequately controlled on metformin: a 24-week, randomized, open-label, activecontrolled study (GetGoal-X). Diabetes Care. 2013;36:2945-51.

13. Seino $\mathrm{Y}$, Akane $\mathrm{T}$, Niemoller $\mathrm{E}$, et al. Long-term safety of once-daily (QD) lixisenatide in Japanese patients with type 2 diabetes (T2DM): GetGoalMono Japan. J Diabetes Investig. 2012;3(Suppl. 1):Abstract PCS-30-5.

14. Seino Y, Min KW, Niemoeller E, et al. Randomized, double-blind, placebo-controlled trial of the oncedaily GLP-1 receptor agonist lixisenatide in Asian patients with type 2 diabetes insufficiently controlled on basal insulin with or without a sulfonylurea (GetGoal-L-Asia). Diabetes Obes Metab. 2012;14:910-7. 
15. Riddle MC, Aronson R, Home P, et al. Adding oncedaily lixisenatide for type 2 diabetes inadequately controlled by established basal insulin: a 24-week, randomized, placebo-controlled comparison (GetGoal-L). Diabetes Care. 2013;36:2489-96.

16. Riddle $\mathrm{MC}$, Forst $\mathrm{T}$, Aronson $\mathrm{R}$, et al. Adding oncedaily lixisenatide for type 2 diabetes inadequately controlled with newly initiated and continuously titrated basal insulin glargine: a 24-week, randomized, placebo-controlled study (GetGoalDuo 1). Diabetes Care. 2013;36:2497-503.

17. Fonseca VA, Alvarado-Ruiz R, Raccah D, et al. Efficacy and safety of the once-daily GLP-1 receptor agonist lixisenatide in monotherapy: a randomized, double-blind, placebo-controlled trial in patients with type 2 diabetes (GetGoal-Mono). Diabetes Care. 2012;35:1225-31.

18. Bolli GB, Munteanu M, Dotsenko S, et al. Efficacy and safety of lixisenatide once daily vs. placebo in people with Type 2 diabetes insufficiently controlled on metformin (GetGoal-F1). Diabet Med. 2014;31:176-84.

19. Ahren B, Leguizamo Dimas A, Miossec P, et al. Efficacy and safety of lixisenatide once-daily morning or evening injections in type 2 diabetes inadequately controlled on metformin (GetGoalM). Diabetes Care. 2013;36:2543-50.

20. Yu Pan C, Han P, Liu X, et al. Lixisenatide treatment improves glycaemic control in Asian patients with type 2 diabetes mellitus inadequately controlled on metformin with or without sulfonylurea: a randomized, double-blind, placebo-controlled, 24-week trial (GetGoal-M-Asia). Diabetes Metab Res Rev. 2014. [Epub ahead of print].

21. Rosenstock J, Hanefeld M, Shamanna P, et al. Beneficial effects of once-daily lixisenatide on overall and postprandial glycemic levels without significant excess of hypoglycemia in Type 2 diabetes inadequately controlled on a sulfonylurea with or without metformin (GetGoal-S). J Diabetes Complications. 2014;28:386-92.
22. Pinget $M$, Goldenberg $R$, Niemoeller $E$, et al. Efficacy and safety of lixisenatide once daily versus placebo in type 2 diabetes insufficiently controlled on pioglitazone (GetGoal-P). Diabetes Obes Metab. 2013;15:1000-7.

23. Type 2 diabetes: national clinical guideline for management in primary and secondary care (update). London: Royal College of Physicians of London; 2008.

24. Inzucchi SE, Bergenstal RM, Buse JB, et al. Management of hyperglycemia in type 2 diabetes: a patient-centered approach: position statement of the American Diabetes Association (ADA) and the European Association for the Study of Diabetes (EASD). Diabetes Care. 2012;35:1364-79.

25. Evaluation of cardiovascular outcomes in patients with type 2 diabetes after acute coronary syndrome during treatment with AVE0010 (lixisenatide) (ELIXA). Available from www.clinicaltrials.gov/ show/NCT01147250. Last accessed April 28, 2014.

26. Food and Drug Administration. FDA announces new recommendations on evaluating cardiovascular risk in drugs intended to treat type 2 diabetes. 2008. Available from http://www.fda. gov/bbs/topics/NEWS/2008/NEW01928.html. Last accessed April 28, 2014.

27. Sivertsen J, Rosenmeier J, Holst JJ, et al. The effect of glucagon-like peptide 1 on cardiovascular risk. Nat Rev Cardiol. 2012;9:209-22.

28. Fineman MS, Mace KF, Diamant M, et al. Clinical relevance of anti-exenatide antibodies: safety, efficacy and cross-reactivity with long-term treatment. Diabetes Obes Metab. 2012;14:546-54.

29. Zealand Pharma A/S. Zealand informs that Sanofi has announced initiation of the LixiLan Phase III clinical program for the Fixed-Ratio combination of Lantus $^{\circledR}$ and Lyxumia $^{\circledR}$. Copenhagen. 2014. Available from: https://newsclient.omxgroup.com/ cdsPublic/viewDisclosure.action?disclosureId=5927 24\&lang=en. Last accessed April 28, 2014. 